\title{
ENTRE CONCEITOS E ACORDOS: AS POLÍTICAS PÚBLICAS PARA A EDUCAÇÃO À (SOB A) LUZ DO BANCO MUNDIAL
}

\section{BETWEEN CONCEPTS AND AGREEMENTS: PUBLIC POLICIES FOR THE EDUCATION ACCORDING TO WORLD BANK}

Flávio de Carvalho*

\begin{abstract}
Resumo: Este artigo tem como objetivo discutir os impactos que a economia e a política neoliberais têm causado na sociedade brasileira a partir da análise crítica do último relatório do Branco Mundial sobre o Brasil. De modo mais específico aqui nos interessa as consequências para o âmbito da educação. Identificamos os conceitos de sociedade e de educação disseminados pelo ideário neoliberal e que se manifestam no relatório, e também nos ocupamos com a relação entre eles e as afirmações e orientações disseminadas no relatório. Além disso, fizemos um cuidadoso exercício de leitura crítica do texto do relatório, e reconhecemos que os interesses do mercado financeiro têm colocado em risco o papel vital da universidade pública, acusando-a de ineficiente quando a real condição da universidade pública no Brasil lhe vincula um indelével papel na construção de um saber nacional e na promoção social de milhões de estudantes brasileiros. Por fim, questionamos os impactos desastrosos que tais orientações causaram e causarão no bem-estar das cidadãs e dos cidadãos brasileiros, aos quais convocamos para a resistência.
\end{abstract}

Palavras-chave: Educação; Políticas Públicas; Banco Mundial; Neoliberalismo; Resistência Política.

Abstract: This paper aims to discuss the impacts that neoliberal economy has caused in Brazilian society, based on the critical analysis of the last report of the World Bank about Brazil. More specifically, we are concerned here with the consequences for the scope of education. We identify the concepts of society and education which are disseminated by neoliberal ideology through the report. We deal with the relationship between these concepts and the assertions and orientations from the report. In addition, we conducted a careful critical reading of this report, whereby we recognize that the financial market's interests have endangered the vital role of the public university, by accusing it of being inefficient. However, the real condition of the public university in Brazil links it to an indelible role in the construction of a national knowledge and in the social promotion of millions of Brazilian students.Finally, we make questions about the disastrous impacts that these guidances has caused and they will cause in the Brazilian citizens' welfare, we call them for resistance.

Key-words: Education; Public Policies; World Bank; Neoliberalism; Political Resistance.

\section{À guisa de considerações iniciais}

Um dos problemas mais graves da vida política na sociedade brasileira não é a corrupção dos representantes políticos, não é a descrença nas instituições que compõem nosso sistema democrático, não é a violência ou a miséria que assola a população. Estes graves e antigos problemas são menores que o problema da apatia social que dia-a-dia consome a cidadania de brasileiras e de brasileiros em todas as regiões do país. Tudo parece insolúvel, então, muitos indivíduos se acomodam e seguem apáticos ou acomodados, conformados, sujeitados na sua labuta diária.

Neste artigo pretendemos indicar alguma esperança na possibilidade de mudança, de reação política, a começar pelo reconhecimento da situação de dominação

\footnotetext{
* Professor Adjunto do Curso de Filosofia na Unidade Acadêmica de Ciências Sociais, Universidade Federal de Campina Grande. flavio.carvalho@ufcg.edu.br
} 
do ideário neoliberal e de seus impactos no nosso dia-a-dia, construindo a partir deste reconhecimento uma postura questionadora, quiçá, fomentar no leitor a proposição de alternativas à economia não humanitária e violenta que nos quer dominar e convencer. Neste sentido, propondo questionamentos de ordem teórica e também de ordem prática, o primeiro movimento do presente artigo diz respeito à indicação da base histórica e filosófica do liberalismo e do neoliberalismo, indo para tanto até o século XVI. Em seguida, trataremos do Consenso de Washington que representa um importante movimento em torno das estratégias de expansão do capital financeiro no século XX. Chegando ao século XXI, focaremos no relatório do Banco Mundial, publicado em novembro de 2017, que trata das indicações (exigências) das quais o estado brasileiro deve se ocupar em vista do equilíbrio econômico, e sub-repticiamente a abertura ao investimento privado e a mercantilização da saúde, da educação e da previdência.

No segundo movimento do artigo abordaremos o texto do referido relatório, forneceremos algumas considerações prévias sobre o relatório do Banco Mundial para o Brasil do ano de 2010 e nos deteremos no relatório de 2017, indicando as questões ali tratadas, além da educação no Brasil, a exemplo da previdência social e dos direitos trabalhistas. Destacamos o fato que o documento é um pacote de afirmações e orientações que se articulam, de modo que as oito questões ali tratadas se alinham no mesmo pensamento neoliberal e, eventualmente, os dados quantitativos são compartilhados entre as questões. Depois de traçar esse panorama do relatório, nos ocuparemos até o final deste artigo com a relação entre o relatório em pauta e a educação brasileira; num primeiro momento nos ocuparemos com a educação básica e em seguida com o ensino superior, adotando a própria disposição do texto do relatório.

Há o terceiro movimento deste artigo, que se imiscui com a descrição do tratamento dado à educação no relatório. Trata-se da nossa análise crítica dos conceitos de educação e sociedade adotados pelo ideário neoliberal, os quais se chocam com valores humanitários ou de direitos civis e trabalhistas adquiridos. Nesta análise também discutiremos as estratégias de privatização, que tendem a aprofundar a discriminação e a desigualdade social em nosso país, e pior ainda, negar direitos fundamentais para a população de acesso à saúde, educação e segurança públicas e de qualidade. Denunciaremos, de modo especial, a mobilização pelo desmantelamento do sistema público de ensino oferecido pelas universidades federais, importantes instituições que trabalham pela qualidade de vida e pelo crescimento da cultura do povo brasileiro e também pelo avanço da ciência e da tecnologia produzidas em território brasileiro. A denúncia se completa quando problematiza a orientação do relatório em vista da cobrança pelos estudos oferecidos nestas instituições e a busca de parcerias que financiem tais instituições.

Entendemos que muitos estudos e análises críticas devem ser realizados sobre todas as partes constituintes do mencionado relatório, pois como citamos acima, muitos elementos da vida social estão em perigo, muitos direitos estão ameaçados pelas afirmações e orientações nele apresentadas. Nossa discussão se pautou em torno da educação e, como educador que sou, convoco todas as educadoras e os educadores deste país à resistência política, a estudarem, a discutirem, a questionarem com seus estudantes em salas de aulas e em conferências os problemas que os documentos do Banco Mundial tem nos trazido e que poderão agravar as dificuldades sociais, ambientais, trabalhistas e financeiras que temos vivido nos últimos anos. Esperamos contribuir, ainda que modestamente, com esta resistência política. 


\section{Antecedentes históricos e filosóficos do neoliberalismo}

Temos presenciado diuturnamente a educação (em toda a complexidade de ideias, elementos e sujeitos que a compõe) se tornar mercadoria. O capital financeiro precisa de expansão para manter o círculo exploratório planejado e articulado pelos donos do capital, e isto conduziu os interesses de lucro para o segmento educacional, e atinge a formação intelectual e cidadã das pessoas. Entretanto, o modo de pensar dos donos do capital não leva em consideração a cultura dos povos, a história das sociedades, a regionalidade dos indivíduos, operando uma homogeneização de estratégias e de procedimentos, seja na produção das mercadorias, seja na criação dos mercados nos quais pretendem obter seus lucros. Assim, a educação, uma vez transformada em mercadoria, deve ser pensada e oferecida para o maior número possível de consumidores, e os donos do capital exigem a retirada quase total do compromisso do Estado com a educação dos cidadãos para que o mercado seja majoritariamente entregue à iniciativa privada.

Esta história da exigência e da respectiva entrega das responsabilidades do Estado nas mãos da iniciativa privada ou dos donos do capital tem um longo percurso, que nos remete ao século XVIII e também à década de 80 do século XX. Precisamos direcionar a atenção para o século XVIII no qual emerge o ideário do liberalismo econômico. Adam Smith ${ }^{1}$, David Ricardo ${ }^{2}$, e o considerado pai do liberalismo (político), John Locke ${ }^{3}$, são alguns dos pensadores que construíram as primeiras ideias do liberalismo econômico e as implementaram, para os quais a crença no livre mercado e no progresso, e também o utilitarismo são conceitos importantes para a compreensão da sociedade, da economia e das relações que entre elas se construirão.

Tratando de modo sintético, o ideário liberal propunha a despolitização da economia, que os assuntos econômicos não sofressem a ingerência dos governos. Convém mencionar que o liberalismo se constrói após e na oposição aos governos absolutistas do período histórico anterior. Neste sentido, os liberais advogavam que os Estados deixassem a cargo dos mercados a criação de suas regulações, criando uma espécie de ordem espontânea nas relações econômicas, principalmente, sobre aquelas que envolviam o dinheiro e o trabalho; quase como um corolário, este liberalismo econômico defende o estado mínimo, no qual a quase ausência do Estado não se limita ao âmbito da regulamentação das relações financeiras, mas também ao de suas responsabilidades sociais com a população. Nestas condições os conceitos de política social e de justiça social são fortemente confrontados, uma vez que o bem estar social e a equidade entre as pessoas não serão considerados para a construção das estratégias financeiras e comerciais. Por fim, o quarto conceito do ideário liberal defendia que a igualdade entre os indivíduos deveria ser reconhecida para efeito de início da atividade econômica, porém, no desenvolvimento cada um deveria garantir-se por suas próprias capacidades, numa espécie de salve-se quem puder.

A questão que nos colocamos neste momento é: quais destas ideias permanecem (ainda que reformuladas) no ideário do neoliberalismo contemporâneo? A nosso ver, o que acontece é a radicalização do ideário liberal do século XVIII, uma vez que na agenda neoliberal, os donos do capital exigem do Estado cada vez mais espaço para expansão dos seus negócios, cada vez mais elementos da vida social precisam se transformar em mercadoria. Atualmente, vemos ascender os interesses neoliberais para dois elementos extremamente importantes da vida social, a saúde e a educação. Se antes

\footnotetext{
${ }^{1}$ Adam Smith publicou sua obra principal em 1776, sob o título de "A Riqueza das Nações".

${ }^{2}$ David Ricardo em 1817 publicou sua obra "Princípios da Economia Política e Tributação".

${ }^{3}$ John Locke publicou sua obra "Dois tratados sobre o Governo" em 1689.
} 
a educação e a saúde eram, como preconiza no Brasil a sua Constituição ${ }^{4}$, direito de todos e dever do Estado, a partir das exigências dos donos do capital, elas se tornam mercadoria para todos na quase ausência do Estado.

Para fornecer algumas informações sobre esta agenda, apenas à guisa de exemplificação, nos remetemos ao ano de 1989, quando se reuniram em Washington, capital dos Estados Unidos da América, diversos representantes de Estados credores e de instituições financeiras, para avaliar a situação política e econômica dos seus devedores, majoritariamente os países da América Latina, e traçar estratégias de reorganização destes mercados. Exatamente, mercados! A nosso ver, os donos do capital consideram os países subdesenvolvidos ou em desenvolvimento como nichos de mercado. Este encontro ficou conhecido como Consenso de Washington, resultou em um conjunto de recomendações dirigidas aos governos dos países devedores, sob a égide de combater as crises e a misérias nestes países, impondo o "fármaco" do ideário neoliberal como solução.

Dizendo de modo sumário, as orientações dos credores aos devedores implicavam em que os países subdesenvolvidos se esforçassem para alcançar o equilíbrio fiscal, que por sua vez implicava em políticas de austeridade fiscal rigorosas, que por sua vez trazia como corolário a necessidade de reformas administrativas, previdenciárias, fiscais, e um severo corte no gasto público. O que de partida deveria gerar mudanças na política e na economia dos países subdesenvolvidos/em desenvolvimento com consequências graves para as cidadãs e os cidadãos, das quais destacamos as implicações para a vida trabalhista, as perdas impostas às trabalhadoras e aos trabalhadores. As exigências dos donos de negócios fomentam (com ares de exigência) a privatização e a desregulamentação, isto é, estimula-se que os Estados abram espaço para o investimento financeiro privado, seja por meio de concessões seja por meio de parcerias, e cobram-se reformas na legislação trabalhista e previdenciária, defendendo, por exemplo, que o mundo do trabalho deve ser regido por regras construídas entre empregadores e empregados e, por fim, sob a justificativa de crise ou colapso dos regimes previdenciários propõem-se o aumento do tempo de contribuição e a redução dos rendimentos dos futuros aposentados, abrindo assim espaço para o comércio dos planos de previdência privados.

Em linhas gerais, estes são alguns poucos conceitos e acordos que se construíram historicamente nas sociedades contemporâneas, selecionamos os mais importantes para o escopo de nossa discussão. Aqui enfatizamos as relações entre os países desenvolvidos (credores) e os países em desenvolvimento ou subdesenvolvidos (devedores), porém, a agenda neoliberal tem sido adotada por todas as economias em nível mundial.

Em vista de aprofundar os impactos deste ideário e desta agenda neoliberal, destarte, nos ocuparemos com a análise do último relatório do Banco Mundial publicado em novembro de 2017, e em vista do objetivo específico do nosso artigo trataremos de modo mais específico o que diz respeito à educação. Convém mencionar que o referido relatório também se dirige aos âmbitos trabalhista, previdenciário e da saúde, tudo eivado pela lógica do estado mínimo, da privatização e da ênfase no gerenciamento

\footnotetext{
4 Art. 196. A saúde é direito de todos e dever do Estado, garantido mediante políticas sociais e econômicas que visem à redução do risco de doença e de outros agravos e ao acesso universal e igualitário às ações e serviços para sua promoção, proteção e recuperação. Art. 205 A educação, direito de todos e dever do Estado e da família, será promovida e incentivada com a colaboração da sociedade, visando ao pleno desenvolvimento da pessoa, seu preparo para o exercício da cidadania e sua qualificação para o trabalho. BRASIL. Constituição da República Federativa do Brasil. Disponível em http://www.stf.jus.br/arquivo/cms/legislacaoConstituicao/anexo/CF.pdf. Acesso em 1 fev. 2018.
} 
estatal eficiente dos recursos do país em detrimento do bem estar social, ainda que se apregoe, demagogicamente, a defesa dos mais pobres.

\section{A educação brasileira e o relatório do banco mundial}

\section{Notas introdutórias sobre os relatórios do Banco Mundial para o Brasil (2010 e 2017)}

Em 2010 o Banco Mundial publicou um relatório intitulado Atingindo uma educação de nível mundial no Brasil: Próximos Passos ${ }^{5}$, o qual representa o estabelecimento de uma agenda de compromissos (leia-se cortes, arrochos e retirada de responsabilidades por parte do Estado) que o governo federal deve implementar sob o pretexto falacioso de alinhar a qualidade do sistema educacional brasileiro ao nível mundial. Em 2017, outro relatório foi publicado sob o título de Um ajuste justo: análise da eficiência e equidade do gasto público no Brasil ${ }^{6}$, o qual se ocupará com questões polêmicas na sociedade brasileira contemporânea, tais como, os gastos públicos do Estado, as reformas trabalhista e previdenciária, e no que diz respeito à educação o título da respectiva seção já prefigura o dano que o relatório pretende causar à educação brasileira: Gastar mais ou melhor? Eficiência e equidade da educação pública.

Convém alertar o leitor para dois pontos importantes e as respectivas posturas necessárias para a empreitada da leitura dos relatórios citados: em primeiro lugar, o uso de falácias representa um recurso extremamente usual nos textos dos relatórios. Denominamos argumento falacioso aquele que aparenta coerência lógica, o qual, todavia, prevê a displicência do receptor da mensagem, que assim não percebe que o argumento prescinde de dados importantes para a dedução lógica, ou que generaliza situações particulares, ou ainda que constrói o argumento apelando para elementos de ordem moral ou emocional; enfim, são variados os modos de construção de argumentos falaciosos, com os quais não nos ocuparemos neste artigo devido a sua finalidade precípua, entretanto, indicaremos na confecção do texto do relatório o uso eventual deste tipo de argumentação; em segundo lugar, o leitor deve estar atento para decodificar quais os conceitos de educação e de sociedade são utilizados e defendidos pelos autores do relatório; compreender os conceitos assumidos pelo texto representa um movimento importante na medida em que se reconhece o conflito entre concepções (de sociedade, dignidade humana, direitos do trabalhador, entre outros) e se percebe a intencionalidade das orientações e providências propostas e também se identifica a quem (grupo ou instituição) o relatório pretende beneficiar, sem se deixar ludibriar, por exemplo, pelo uso reiterado da expressão "os mais pobres".

Em ambos os relatórios devemos problematizar a sistemática exaltação dos mecanismos de avaliação adotados pelo Estado (SAEB, Prova Brasil/Provinha Brasil, IDEB, ENEM, Provão, ENADE), que se alinham com as políticas internacionais de investimento tendo como referência a OCDE. A questão fulcral assumida por estes mecanismos não se localiza na qualidade pedagógica, de formação cidadã e cultural dos

\footnotetext{
${ }^{5}$ GRUPO BANCO MUNDIAL. Atingindo uma educação de nível mundial no Brasil: Próximos Passos. $2010 . \quad$ Disponível em: http://portal.mec.gov.br/index.php?option=com_docman\&view=download\&alias=7289-banco-mundialpdf\&Itemid=30192. Acesso em: 1 dez. 2017.

${ }^{6}$ GRUPO BANCO MUNDIAL. Um ajuste justo: análise da eficiência e equidade do gasto público no Brasil Disponível em: http://documents.worldbank.org/curated/pt/884871511196609355/pdf/121480REVISED-PORTUGUESE-Brazil-Public-Expenditure-Review-Overview-Portuguese-Final-revised.pdf. Acesso em: 1 dez. 2017.
} 
jovens estudantes, o elemento principal diz respeito ao quanto melhor deve ser o desempenho dos estudantes em vista das demandas do mercado de trabalho. Se a preocupação fosse com a formação de cidadãs e cidadãos mais comprometidos com o bem estar social (e não apenas o investimento financeiro e o lucro) os relatórios deveriam fazer referência à organismos internacionais que se ocupam com a educação para além da lógica do capital. Em momento algum, os relatórios fazem menção, à guisa de exemplo, dos documentos da UNESCO para a sustentabilidade ou sobre os compromissos sociais da educação; quando se referem a esta organização se utilizam apenas de dados estatísticos sobre gastos e sobre reprovações de estudantes.

Mediante as observações feitas, isto é, a atenção para a construção de argumentos falaciosos e o questionamento acerca dos conceitos de educação e sociedade presentes no texto, vamos nos deter na análise do relatório de 2017, uma vez que este passa a ser o "manual" a ser seguido pelo atual governo. Antes, porém, cumpre-nos destacar os seguintes elementos e orientações do relatório de 2010, que oportunamente voltam atualizados (e radicalizados) na versão de 2017: as reformas de modernização e de aumento da eficácia do Estado visam o aumento da capacidade de mercado, isto é, sob a alegação de se tornar mais eficaz o Estado reduz seus investimentos em vista de abrir espaço para o empreendimento privado, seja na educação seja na saúde ou mesmo na segurança; o problema do analfabetismo e da não universalidade da educação pública de qualidade divide território com a mercantilização da educação e a privatização deste setor, numa disputa em que preocupações como a formação humana dos jovens estudantes, a crescente onda de violência nas escolas e a existência do analfabetismo funcional não são objeto de preocupação dos autores do relatório. Entendemos que o relatório do Banco Mundial é um texto técnico e burocrático sobre estratégias econômicas e financeiras, entretanto, este objetivo não pode prescindir ou mesmo agredir elementos e situações sociais e existenciais.

Em novembro de 2017, foi publicado o documento Um ajuste justo: análise da eficiência e equidade do gasto público no Brasil, o mais recente relatório do Banco Mundial dirigido ao Brasil. No prefácio, os redatores indicam a motivação e o propósito do documento ${ }^{7}$ :

\begin{abstract}
Atento à mudança de cenário, o governo federal solicitou ao Banco Mundial a elaboração deste relatório, com o objetivo de realizar uma análise aprofundada dos gastos do governo, identificar alternativas para reduzir o déficit fiscal a um nível sustentável e, ao mesmo tempo, consolidar os ganhos sociais alcançados nas décadas anteriores. O principal achado de nossa análise é que alguns programas governamentais beneficiam os ricos mais do que os pobres, além de não atingir de forma eficaz seus objetivos. Consequentemente, seria possível economizar parte do orçamento sem prejudicar o acesso e a qualidade dos serviços públicos, beneficiando os estratos mais pobres da população.
\end{abstract}

Trata-se, portanto, de um documento cujo objetivo se circunscreve ao âmbito dos gastos públicos na esfera do governo federal, fica evidente que todos os elementos tratados no decorrer do texto são reconhecido como fontes de "gastos", não interessarão questões vinculadas às situações apresentadas, tais como, má distribuição de renda, violência, insalubridade nas condições de trabalho, pois o escopo de análise do relatório

${ }^{7}$ GRUPO BANCO MUNDIAL. Um ajuste justo: análise da eficiência e equidade do gasto público no
Brasil. 2017.
Disponível http://documents.worldbank.org/curated/pt/884871511196609355/pdf/121480-REVISEDPORTUGUESE-Brazil-Public-Expenditure-Review-Overview-Portuguese-Final-revised.pdf Acesso em: $1 \mathrm{dez} 2017$, p. 1. 
diz respeito ao quanto se gasta, quanto se pode reduzir tais gastos (sem considerar se há perdas na qualidade de vida das pessoas) e como se pode otimizar o retorno de tais gastos para o mercado de trabalho e a geração de mais capital. Como já mencionado, destacamos a utilização da expressão "mais pobres", a qual será utilizada diversas vezes, sendo porém elemento de convencimento emocional, na medida em que não se problematizam as situações que constrói a massa de mais pobres na população brasileira.

O documento divide sua atenção com questões fulcrais, problemáticas e polêmicas para a sociedade brasileira contemporânea. A primeira questão do relatório se dedica aos desafios para a sustentabilidade fiscal no Brasil, na qual destacamos a orientação para a adoção do teto de gastos; a segunda questão aparece no título da seção e já demarca o posicionamento dos seus redatores ao enfatizar o peso da folha do funcionalismo público, peso este que será reforçado pela comparação (que mais se assemelha à tentativa de jogar setores um contra o outro), na estimativa da lacuna entre o setor público e o privado, tratando das remunerações; a terceira questão diz respeito às compras públicas: planejamento e estratégias de licitações para a eficiência fiscal; a quarta questão é tratada com a parcialidade típica dos redatores mais uma vez, quando o título indica Previdência social: uma conta impagável, cujo texto vai reforçar o discurso do governo federal na atualidade quanto ao déficit nas contas da previdência social, apontando para a necessidade de reforma urgente, comparando os índices de remuneração praticados no Brasil com os índices internacionais de países nos quais o ideário neoliberal vigora fortemente no controle dos governos; o relatório trata de uma quinta questão, os Programas de apoio ao mercado de trabalho e assistência social: integrar para melhorar; a parcialidade aqui divide espaço com o objetivo precípuo do documento, o fomento ao mercado de trabalho; a sexta questão são as reformas pretendidas em vista de aumentar a eficiência, a equidade e a economia fiscal, questões encimadas pelo título Saúde: alternativas para oferecer mais e melhores serviços; a sétima questão, objeto da discussão do presente artigo, por ora destacaremos apenas a parcialidade dos redatores quando sobrescrevem o título Gastar mais ou melhor? Eficiência e equidade da educação pública, fiquemos, entretanto, pensando se trata de gastar ou investir? qual conceito há subjacente ao uso do verbo?; a oitava questão abordada pelo relatório manifesta a defesa explícita do capital privado como estímulo ao crescimento econômico do país, o título Políticas de apoio ao setor privado dão retorno à sociedade? colima esforços de justificar a eventual retirada de responsabilidade da administração pública em vista da garantia do espaço para o capital privado.

Como afirmamos o nosso objetivo neste artigo diz respeito à análise crítica do relatório na seção que trata dos assuntos relacionados à educação, porém, cumpre-nos destacar que o relatório é um pacote, é um coletivo de orientações e prescrições que se articulam, que justificam o arrocho e os cortes nas contas públicas, a mercantilização da saúde e da educação, bem como, em vários momentos, apregoa a importância para o desenvolvimento econômico observar a coerência de gastos e a responsabilidade com a sustentabilidade financeira com que trabalham, segundo os redatores, as administrações privadas, o que justificaria de partida a estratégia das privatizações no setor público.

\section{A educação brasileira tratada como mercadoria}

Numa leitura apressada e desatenta, o texto do relatório do Banco Mundial de 2017 aparentemente preserva a preocupação com o equilíbrio dos gastos públicos e com a equidade quanto ao oferecimento à população dos serviços públicos de educação em nível superior, sob esta aparente preocupação com "os mais pobres" e sob esta aparente 
indignação de que "os mais ricos" estão se beneficiando destes serviços, o relatório declara o que outrora não houvera ousadia de propor, a cobrança de mensalidade nas universidades públicas federais. Este talvez seja o maior malefício que o atual relatório comporta. Aos jovens estudantes oriundos de famílias ricas competiria o pagamento das mensalidades com suas próprias rendas, aos jovens estudantes oriundos de famílias pobres competiria recorrer ao FIES (Fundo de Financiamento Estudantil), que a partir de 2018 foi estendido aos bancos privados além dos bancos estatais. Ainda que neste primeiro momento, a adesão aos bancos privados esteja limitada a apenas uma das três linhas de financiamento, o fato é que o governo, a nosso ver, se alinhou e cedeu às exigências do capital privado, isto é, o Estado recua em suas responsabilidades para que o avanço da iniciativa privada aconteça.

O relatório reconhece que o gasto médio por aluno no ensino não é alto, porém, pondera que é consideravelmente elevado nas universidades públicas e nos institutos federais, e declara que tal custo é aproximado do montante gasto por países com o dobro do PIB per capita. E declara "Além do mais, alunos nas universidades públicas brasileiras em média custam de duas a três vezes mais do que alunos matriculados em universidades privadas" ${ }^{8}$. Convém destacar que o relatório trabalha com generalizações embasadas em resultados quantitativos, e propositalmente negligencia o problema da qualidade do ensino oferecido por um grande número de instituições de ensino superior privadas. Trata-se de argumentos técnicos, de pessoas que desconhecem (ou dissimulam conhecer) o dia-a-dia do ensino superior privado no Brasil, desde problemas estruturais como salas de aulas superlotadas, ao aumento exponencial da oferta de disciplinas online (sob a alegação de incentivo à inclusão digital), passando pelas dificuldades nas relações trabalhistas com o corpo docente. Os leitores do relatório podem desconhecer os dados quantitativos lá expostos, entretanto, os redatores igualmente "desconhecem" a vida real do ensino superior privado.

Neste momento inicial nos ocupamos com estas observações em relação ao ensino superior, devido aos seus impactos potenciais. Porém, optaremos por seguir a ordem do texto do relatório, sendo assim, trataremos a partir de agora das afirmações e orientações do relatório em relação à educação básica (ensino fundamental e médio).

Surpreende o tipo de argumentações apresentado no relatório com base em observações precárias do fenômeno social da educação. Os redatores entendem que gasto em educação e eficiência são os elementos que se devem considerar para efeito de análise, e no caso do relatório estes elementos têm exclusividade. Assim, se o gasto não produz o resultado esperado o problema está no gerenciamento do montante e para demonstrar o argumento se indicam situações análogas de outros países da OCDE (Organização de Cooperação e de Desenvolvimento Econômico) que passam a figurar como parâmetro de mensuração para o ajuste e para a reforma de gerenciamento dos gastos no Brasil. Note-se o que o relatório afirma sobre a eficiência dos gastos com educação no ensino fundamental e médio 9 :

O desempenho brasileiro medido pela prova de matemática do PISA em 2012 foi somente $83 \%$ do esperado para países com o mesmo nível de gasto por aluno (...). Países como a Colômbia e a Indonésia, por exemplo, atingiram pontuações semelhantes no PISA gastando bem menos por aluno. Já países como Chile, México e Turquia gastam valores similares ao Brazil [sic] e obtêm melhores resultados.

${ }^{8}$ Op. cit, p. 123.

${ }^{9}$ Op. cit., p. 124. 
Diversas problematizações são possíveis apenas neste trecho. Primeiramente, como medir a eficiência no sistema de ensino de um país tomando em consideração apenas os resultados de uma área específica dos saberes, além disso, se trata de resultados mensurados por um medidor internacional vinculado a $\operatorname{OCDE}^{10}$, a organização que se ocupa com a dinâmica do mercado de capital é o mesmo que gerencia a avaliação; em segundo lugar, problematizamos o fato que são ignoradas diferenças sociais de toda sorte que se verificam entre os países, como se qualquer política educacional de investimento na educação prescindisse de variáveis como peculiaridades geográficas e históricas da formação da nação e do país em questão, as desigualdades na distribuição de renda e os problemas de ordem política como a corrupção, as diferenças de ordem étnica e as questões de gênero. Constitui-se em postura bizarra, estabelecer relação entre gasto e eficiência tomando como parâmetro apenas o PIB per capita ou qualquer outro elemento de ordem apenas financeira. Mais uma vez fica evidente que os redatores do relatório não conhecem (não consideram) a dinâmica da educação enquanto construção de saber e enquanto formação humana.

Outros exemplos de desconhecimento ou desconsideração da diversidade de elementos que constituem o fenômeno social chamado educação podem ser encontrados no relatório. Em um trecho se afirma que "O baixo desempenho do sistema educacional brasileiro reflete-se nas altas taxas de reprovação e evasão escolar, apesar das baixas e decrescentes razões aluno-professor ${ }^{11}$." e mais adiante considera que "O baixo índice de conclusão do ensino médio é outro indicador do baixo desempenho do sistema educacional. ${ }^{12}$ ". E quando parece que outros elementos serão considerados na análise a decepção se manifesta, pois apesar do relatório reconhecer que "As reprovações não somente são custosas, mas também refletem a falta de apoio dirigido aos alunos com desempenho mais fraco - geralmente de famílias desfavorecidas. ${ }^{13}$ ", o reconhecimento fica no vácuo, pois o problema não é desenvolvido no seguimento do texto, tampouco é retomado em outro momento do relatório. Ficando, então, subentendido que a escola não presta o auxílio necessário, porém, não se problematiza as causas sociais, econômicas e governamentais para a existência de tais famílias desfavorecidas, tampouco se discute, ainda que sob o invés de gastos, o que pode ser feito para diminuir ou erradicar este problema nas escolas.

Para abordar ambos os casos (reprovação e evasão) o relatório dirige seu foco para a razão professor-aluno e entende que apesar desta razão no caso do Brasil estar abaixo da média internacional, ter poucos alunos em uma sala de aula não garante a eficiência no tratamento dos problemas em pauta. Fica subentendido, então, que se deve aumentar esta razão, por meio do contingenciamento na contratação de futuros professores pois, isto representará ganho na relação gasto-eficiência, como ficará

\footnotetext{
${ }^{10}$ Convém lembrar que o PISA tem funcionado como instrumento de definição de políticas educativas nos países que o utilizam e também que suas avaliações seguem o roteiro de três avaliações em ciclos de três anos, e em cada avaliação se mensura o rendimento de uma área específica, a saber, Matemática, Leitura e Ciências. No Brasil em 2000 e 2009 avaliou-se a área de Leitura, em 2003 e 2012 avaliou-se a área de Matemática, em 2006 e 2015 avaliou-se a área de Ciências; o cronograma da avaliação em 2018 já está disponível no site do INEP http://inep.gov.br/pisa

${ }^{11}$ GRUPO BANCO MUNDIAL. Um ajuste justo: análise da eficiência e equidade do gasto público no Brasil. 2017. Disponível em: http://documents.worldbank.org/curated/pt/884871511196609355/pdf/121480-REVISEDPORTUGUESE-Brazil-Public-Expenditure-Review-Overview-Portuguese-Final-revised.pdf Acesso em: $1 \mathrm{dez} 2017$, p. 125.

${ }^{12}$ Op. cit., p. 125.

${ }^{13}$ Op. cit., p. 126.
} 
evidente em trechos seguintes do relatório, ficando esquecidos os problemas que abriram a exposição:

\begin{abstract}
As baixas razões aluno-professor ${ }^{14}$ são um problema significativo no ensino fundamental nas regiões Sul, Sudeste e Centro-Oeste, onde mudanças demográficas estão causando uma queda rápida no número de alunos das redes públicas. Em grande parte, esse problema poderia ser solucionado por meio da não reposição de parte dos professores que estarão se aposentando em breve. A redução do número de professores por meio da aposentadoria poderia ajustar as razões a níveis eficientes no ensino fundamental até 2027 e, no ensino médio, até 2026.
\end{abstract}

E acrescenta em nota de rodapé outra manobra para o corte de gastos, desta feita atingindo os regimes de previdência, corroborando o que já afirmamos acerca do relatório ser um pacote de orientações e providências sistêmicas ${ }^{15}$ :

Vale destacar que, devido às generosas regras previdenciárias dos
professores, os aposentados do setor ainda impõem custos orçamentários aos
estados e municípios por meio do sistema previdenciário. Ganhos fiscais
imediatos somente serão realizados se o declínio natural no número de
professores for acompanhado por uma reforma dos RPPSs subnacionais.

Consideramos tarefa árdua indicar o momento mais controverso ou polêmico no texto do relatório, entretanto, além da indicação para a cobrança de mensalidades nas universidades públicas - mencionada acima e que voltaremos a tratar - há um momento no relatório que tangencia o achincalhamento da educação brasileira e também da profissão de professor. Não é necessário esforço interpretativo, posto que o texto é explicitamente claro ao afirmar "O magistério permanece uma profissão desprestigiada. Os requisitos para ingresso em cursos de licenciatura são fracos e a formação é de baixa qualidade.". E continua "além da pouca seletividade na contratação de professores para os sistemas educacionais estaduais e municipais, os salários não são vinculados do desempenho. ${ }^{16 "}$.

De modo oportuno e conveniente para si, o relatório emite tais considerações sem remeter a documento algum, sem indicar gráfico estatístico algum, tampouco faz referência a investigações científicas ou acadêmicas sobre o tema da formação de professores no Brasil ou sobre a atuação do profissional de educação no Brasil. Por que um relatório de uma instituição internacional emite tais ajuizamentos sem indicar sequer uma referência acadêmica ou científica? Esta é uma primeira questão. Em segundo lugar, convém indagar o que historicamente foi feito pelo Estado brasileiro que viabilizou o desprestígio mencionado? A propósito, convém também perguntar o que os redatores entendem por desprestígio da profissão? Em terceiro lugar, qual parâmetro está sendo utilizado e a quais instituições de formação de professores o relatório se refere quando afirma a fraqueza dos requisitos de ingresso e, principalmente, quando acusa os cursos de licenciatura de baixa qualidade? A argumentação falaciosa de generalização aqui apresentada tanto causa indignação quanto desperta ainda mais a incredulidade sobre os redatores deste relatório, os quais aparentam não ser especialistas em educação (nem se ocupam em ter assessorias de tais especialistas) e tampouco parecem conhecer a realidade da vida educacional em seu locus. Por fim, como garantir a validade do argumento acerca da diferença entre os salários pagos no Brasil e em

${ }^{14}$ Op. cit., p. 129.

${ }^{15}$ Op. cit., p. 129.

${ }^{16}$ Op. cit., p. 127. 
outros países quando não se teve a coerência metodológica de indicar se os padrões de formação de professores destes outros países são melhores ou piores que os do Brasil. A nosso ver, como professor e como formador de professores, o relatório é oportunista quando recorta para a exposição apenas os elementos que lhe favorecem, bem como é infundado em seus ajuizamentos sobre a formação de professores no Brasil quando emite opiniões sem amparo em sólida investigação acadêmica e científica.

Uma das soluções apontada pelo relatório gera no mínimo o acirramento das relações entre os cidadãos das diversas regiões do Brasil, quando propõe que os investimentos sejam reduzidos no sul, sudeste e centro-oeste e aumentados no norte e nordeste ${ }^{17}$.

\begin{abstract}
Os municípios e estados do Norte e Nordeste tendem a ser mais eficientes, e recursos adicionais teriam um impacto maior nessas regiões (Figura 94). Na verdade, a redução dos gastos nessas regiões poderia afetar negativamente o desempenho. Para as escolas nos estados e municípios das regiões Sul, Sudeste e Centro-Oeste que gastam mais por aluno, a redução dos gastos não parece pôr em risco os resultados. Essas tendem a ser menos eficientes e poderiam se beneficiar mais com melhoras na gestão.
\end{abstract}

Parece ser uma estratégia dos redatores do relatório, a aparente preocupação com questões estruturais e sociais em vista de preservar certo caráter social, quando na verdade o elemento que define prioridades ou que encaminha ajustes e cortes é a relação gasto e eficiência. Ora, não nos iludamos! A prioridade defendida para a região Nordeste não está no fato que se considere necessário corrigir a desigualdade que definiu as relações entre o governo federal e as regiões Norte e Nordeste do Brasil ao longo da história da sociedade brasileira, a prioridade defendida se deve ao fato que o relatório pondera que enquanto estas regiões têm baixo investimento e conseguem ainda assim ter boa eficiência (a figura 94 do relatório ilustra esta distribuição), as regiões Sul e Sudeste têm alto investimento e precisam melhorar a eficiência (sobretudo quanto à razão professor-aluno). O foco parece ser o aumento, mas o objetivo é a redução de gastos.

A partir deste momento, trataremos das afirmações e orientações que o relatório do Banco Mundial dirigiu ao governo federal sobre o ensino superior, notadamente sobre as universidades públicas federais. Note-se que o espaço de análise dos gastos com ensino superior, apesar de ocupar menos páginas (131 - 138) que a análise dos gastos com ensino fundamental e médio (121 - 131), tem uma força de destruição incomparável, na medida em que de uma só vez pretende-se retirar direitos dos trabalhadores do magistério superior, retirar a gratuidade do ensino superior público e desqualificar a atuação da universidade pública, enquanto convenientemente se exalta o desempenho dos Institutos Federais de Educação, Ciência e Tecnologia.

O primeiro conjunto de argumentos pretende demonstrar que as universidades públicas recebem os jovens oriundos dos grupos mais ricos da sociedade brasileira, e que os custos com um estudante em universidade pública é cinco vezes superior ao custo em universidade privada; e com base na sua análise dos dados do ENADE os redatores afirmam que "A pontuação média do ENADE para universidades públicas é maior do que para as privadas (Figura 98). No entanto, estudantes que entram nas universidades públicas tendem a já terem atingido um maior nível de aprendizado antes mesmo de iniciar os estudos. ${ }^{18}$ " Portanto, concluem que o valor adicionado não está diretamente ligado à universidade pública: "e universidades federais adicionam por volta do mesmo valor por estudante do que universidades privadas sem fins lucrativos,

${ }^{17}$ Op. cit., p. 129.

${ }^{18}$ Op. cit., p. 132. 
no entanto, elas custam cerca de três vezes mais. ${ }^{19}$ " Segue-se uma extensa argumentação que compara a eficiência e os gastos no âmbito das universidades privadas, tomadas como exemplares, com os dados no âmbito das universidades públicas. A questão que se coloca neste momento é: porque os redatores neste momento do relatório estão apelando para a comparação entre universidades públicas e privadas?, mudando a estratégia utilizada para a análise da eficiência e gastos no caso do ensino básico; enquanto no estudo anterior se comparavam os índices brasileiros com os índices internacionais, aqui se comparam, majoritariamente, os índices da iniciativa privada com os da pública. Ora, a mercantilização da educação superior, que tem feito crescer a circulação de ações nas bolsas de valores daquelas empresas ligadas a este segmento de mercado, não aparece aí explicitamente, porém, fomenta este tipo de argumentação, e apela também para a desqualificação da universidade pública.

Entretanto, há discursos outros, discursos críticos e de oposição, sendo produzidos e divulgados. O presidente da ANDIFES (Associação Nacional dos Dirigentes de Instituições Federais de Ensino Superior), reitor Emmanuel Zagury Tourinho, antes mesmo da divulgação do relatório do Banco Mundial em 2017, opunhase à alegação de problemas na gestão das universidades públicas federais, a qual segue disseminada por quem tem interesse no desmantelamento do ensino público gratuito e de qualidade no Brasil. Quando ocorreu o lançamento do caderno "Universidades Federais: patrimônio da sociedade brasileira" ${ }^{20 "}$ o Prof. Tourinho explicou que "Nosso objetivo, com esse caderno, é apresentar informações relevantes e esclarecer que não há crise de gestão, mas, sim, há falta de continuidade nas políticas de financiamento das universidades federais" ${ }^{21}$. O caderno traz uma importante argumentação acerca do papel das universidades federais, inclusive informando dados sobre a evolução dos investimentos em educação no Brasil e confrontando dados com os países da OCDE. Desse modo, usa uma fonte abundantemente utilizada pelos redatores do relatório em pauta para mostrar que o investimento brasileiro é um dos mais baixos. Tomando a tabela 1 do referido caderno veremos que o investimento brasileiro por matrícula fica atrás somente do México, sendo superado pelos demais países constantes na tabela ${ }^{22}$. $\mathrm{O}$ caderno insiste na divulgação da informação acerca da descontinuidade nas políticas de financiamento das universidades federais, que se manifesta nos reiterados cortes e restrições impostos sobre as IFES (Instituições Federais de Ensino Superior) e que tende a se agravar depois da aprovação do congelamento de gastos pela Emenda Constitucional 95 de dezembro de 2016 sobre a qual o documento da ANDIFES faz o seguinte prognóstico ${ }^{23}$ :

o cenário para as próximas duas décadas é de intensificação de um processo que poderá levar ao comprometimento definitivo do Sistema Público de Universidades Federais, com impactos desastrosos para o desenvolvimento econômico e social do país, para o enfrentamento da pobreza e da desigualdade e, enfim, para a soberania nacional.

\footnotetext{
${ }^{19}$ Op. cit., p. 133.

20 ANDIFES. Universidades Federais: patrimônio da sociedade brasileira. Disponível em: http://www.andifes.org.br/wp-content/uploads/2017/11/Andifes-VERSAO-DOWNLOAD-REDESSOCIAIS-E-WHATSAPP.pdf

21 Disponível em : http://www.andifes.org.br/andifes-publica-caderno-em-defesa-das-universidadesfederais/ Acesso em : 5 fev.2017

22 ANDIFES. Universidades Federais: patrimônio da sociedade brasileira. Disponível em: http://www.andifes.org.br/andifes-publica-caderno-em-defesa-das-universidades-federais/ Acesso em: 5 fev.2017, p. 8.
}

${ }^{23}$ Op. cit., p. 10. 
Outro ponto marcante do caderno diz respeito ao reconhecimento social da qualidade e da importância do sistema público de universidades federais, que ao contrário da propaganda de achincalhamento promovido no relatório do Banco Mundial informa como as IFES são respeitadas e reconhecidas, quer pelos membros da sociedade quer por agências de avaliação e de fomento como o INEP, a CAPES, reconhecidas inclusive por entidades não governamentais, como se pode observar nas publicações de rankings de instituições e de cursos brasileiros. O documento da ANDIFES ainda destaca que ${ }^{24}$

\begin{abstract}
Empresas públicas e privadas, de todos os setores da economia nacional, premiam e buscam apoio das Universidades Públicas Federais, visando ganhar eficiência e competitividade. Está nas Universidades Federais a mais ampla e eficiente rede de Núcleos de Inovação Tecnológica, em apoio à verticalização e incorporação de tecnologia de ponta nas cadeias produtivas nacionais.
\end{abstract}

Convém destacar a expressão utilizada no documento da ANDIFES, quando preconiza o papel das universidades federais, para o que denomina de "projeto de nação" com vistas à formação de uma inteligência nacional, domínio de conhecimento de ponta, superação da pobreza e da desigualdade, soberania, cidadania e democracia ${ }^{25}$. E neste sentido, aquela Associação, defendendo a continuidade dos benefícios que as IFES oferecem ao Brasil, propõe: i) a recomposição, atualização e correção dos orçamentos destinados às IFES, ii) o respeito integral à autonomia das universidades, iii) a construção feita pelo governo federal e pela sociedade de um programa de expansão pautado pela meta 12 do PNE (Plano Nacional de Educação), iv) a atualização do Programa Nacional de Assistência Estudantil, v) a recomposição das agências de fomento e o repasse integral às instituições dos recursos do Fundo Nacional de Desenvolvimento Científico e Tecnológicos, hoje destinados ao pagamento de juros no mercado financeiro.

Um documento desta envergadura se não destrói a argumentação ofensiva e ostensiva dos redatores do relatório do Banco Mundial quando se referem às IFES, ao menos coloca sob questionamento o uso de dados da OCDE e também provoca o leitor a questionar as acusações de ineficiência alardeadas no referido relatório.

Voltando ao texto do relatório há um trecho que fazemos questão de transcrevê-lo na íntegra, em vista de evidenciarmos a ausência de coerência lógica (e ausência de real preocupação com o bem-estar social) entre a reiterada defesa da superação da desigualdade social e a defesa da cobrança pelos estudos em universidades públicas. O texto afirma ${ }^{26}$ :

192. Os retornos do ensino superior são altos no Brasil, o que justificaria deixar que os estudantes paguem pela própria educação. Embora os retornos do ensino superior tenham se reduzido um pouco nos últimos anos, eles permanecem altos no Brasil (Figura 104). Estudantes de famílias mais ricas têm acesso a ensino superior gratuito, o que aumentará sua renda futura.

\footnotetext{
${ }^{24}$ Op. cit., p. 7.

${ }^{25}$ Op. cit., p. 11.

${ }^{26}$ GRUPO BANCO MUNDIAL. Um ajuste justo: análise da eficiência e equidade do gasto público no Brasil. Novembro de 2017. Disponível em: Disponível em: http://documents.worldbank.org/curated/pt/884871511196609355/pdf/121480-REVISED$1 \mathrm{dez} 2017$, p. 136.
} 
Portanto, o ensino superior gratuito pode estar perpetuando a desigualdade no país.

Primeiramente, qual a relação de implicação entre o retorno profissional e salarial que o ensino superior pode futuramente oferecer e a justificativa de pagamento pela formação escolar? Isto é o que temos chamado de argumento falacioso, não há ligação lógica entre a premissa e a conclusão. Em segundo lugar, o chamado retorno do ensino superior reconhecido pelo texto como "se reduzindo nos últimos anos" está ainda mais comprometido, uma vez que a reforma trabalhista aprovada em 2017 tornou o cenário trabalhista para qualquer nível de formação escolar o pior possível, na medida em que o controle da negociação da mão de obra foi entregue aos homens de negócios. Em terceiro lugar, afirma-se que "Estudantes de famílias mais ricas têm acesso a ensino superior gratuito, o que aumentará sua renda futura ${ }^{27}$ "; perguntamos novamente qual a relação de implicação lógica neste argumento? Como a gratuidade oferecida de hoje aumentará a renda futura daquele que a recebe? É tão pífia a argumentação que chega a causar vergonha de quem redigiu. E por fim, a afirmação que o ensino superior gratuito pode estar perpetuando a desigualdade supõe a ignorância de milhares de histórias de estudantes das camadas mais pobres da sociedade, que encontraram nos estudos vivenciados nas universidades públicas o seu caminho para a melhoria de vida pessoal, familiar e muitas vezes da sua comunidade inteira. Destacamos, mais uma vez que quem redigiu este relatório não tem vivência efetiva na educação pública, seja na escola básica seja no ensino superior, escrevem como especialistas de gabinete, leitores de tabelas estatísticas, que não dialogam com especialistas engajados e militantes na educação brasileira, tampouco se dão ao trabalho de conhecer a vida das pessoas para além das cifras e percentagens.

$\mathrm{Na}$ última parte deste item do relatório, que tratou da relação gasto e eficiência na educação, os redatores ficaram extremamente à vontade para defender o pagamento dos estudos nas universidades públicas e, além disso para indicar como estratégia para melhorar a gestão a implantação do modelo de escolas charter. O texto afirma: "A contratação de empresas privadas para o fornecimento de serviços de educação também poderia melhorar o desempenho e a eficiência dos gastos públicos com educação. As escolas charter provavelmente teriam mais flexibilidade para gerir seus recursos humanos. ${ }^{28}$ ". Esta proposta trata não apenas de retirar a autonomia da gestão escolar dos membros que compõem a comunidade escolar, também diz respeito à entrega ao mercado financeiro de mais um segmento da atividade social para a obtenção de lucros, posto que que o regime de administração adotado nas chamadas escolas charter requer a existência de "empresas privadas sem fins lucrativos" especializadas em gestão, denominadas de Organização Social (OS) e há outro modelo, as Organização da Sociedade Civil de Interesse Público (OSCIP). Esta experiência em que o Estado entrega a gestão das escolas nas mãos da iniciativa privada foi criada nos Estados Unidos, atualmente, outros países a exemplo do Chile e de Portugal também adotam este modelo de gestão, e no Brasil a experiência já foi utilizada pelos estados de Pernambuco, Ceará e Goiás.

O termo charter (contrato, em língua inglesa) já indica o tipo de relação que se cria entre Estado e iniciativa privada, pois o Estado contrata determinada associação ou fundação que a partir do contrato firmado passa a ser denominada de Organização Social. Esta, com o incentivo do Poder Público, passa a desempenhar aqueles serviços sociais não exclusivos do Estado embora sob a sua fiscalização. Na prática da gestão

${ }^{27}$ Op. cit., p. 136.

${ }^{28}$ Op. cit., p. 137. 
escolar o diretor não trata mais as questões administrativas, a ele compete as questões pedagógicas (as relações de ensino-aprendizagem que envolvem professores, alunos e comunidade escolar) e à OS passam-se as responsabilidades pelo gerenciamento de pessoal, de manutenção do patrimônio, de aquisição de materiais, e todas as tarefas administrativas. Há abundante material disponível na internet sobre a história, o funcionamento, os prós e os contras da adoção deste tipo de parceria. O que nos interessa neste momento é lançar o destaque sobre esta proposta abertamente declarada no relatório, que ratifica o que vimos afirmando desde as primeiras páginas: o relatório do Banco Mundial corresponde ao discurso (ao comando) dos homens de negócio para obter mais mercado para o capital financeiro; o conceito de educação que o relatório entende e defende se vincula à esta lógica da mercantilização, e quase como corolário, a oportunidade para a iniciativa privada avançar depende do recuo do Estado.

O último trecho do relatório acerca da educação ainda trata do ensino superior, e após certo comedimento na argumentação em defesa dos corte de investimentos e abstenção de responsabilidades do setor público para ceder lugar à iniciativa privada, os últimos parágrafos não tem mais pudores sociais e afirma ostensiva defende as ações prementes: "Limitar os gastos (grifo nosso) por aluno aos níveis das universidades mais eficientes geraria uma economia imediata de $0,26 \%$ do PIB. ${ }^{29}$ ". Onde estão a postura pedagógica ou a preocupação com a desigualdade social? O texto ainda propõe: "As universidades que receberem menos recursos como resultado desta medida teriam de reconsiderar sua estrutura de custos e/ou buscar recursos em outras fontes. ${ }^{30 "}$ (grifo nosso). Está decretada a corrida das IFES às parcerias com as empresas privadas, e neste sentido, os cursos de graduação e de pós-graduação de áreas do saber que não tivessem uma mercadoria lucrativa em curto prazo para negociar com tais empresas ficariam relegadas à penúria de recursos. Mais adiante o texto afirma: "Uma opção para aumentar os recursos das universidades federais sem sobrecarregar o orçamento seria a introdução de tarifas escolares. ${ }^{31}$ ". Perguntamos novamente onde está a preocupação com a formação das novas gerações ou com a desigualdade social apregoada? E em seguida o relatório pondera e comemora: "Paralelamente, é necessário facilitar o acesso a mecanismos de financiamento para estudantes que não possam pagar as mensalidades. Felizmente, o Brasil já possui o programa FIES, (...)" e complementa o relatório: "A ampliação do FIES para incluir universidades federais poderia ser combinada ao fornecimento de bolsas de estudos gratuitas para os estudantes dos $40 \%$ mais pobres da população, por meio do programa PROUNI. ${ }^{32}$ " Quanto a estas orientações, o que há de fato em relação ao PROUNI está no âmbito do compromisso do governo federal com sua ampliação, entretanto, o que há de fato em relação ao FIES está no âmbito do efetivo, isto é, foi autorizado em 2017, como já informamos acima, a partir de 2018 o FIES foi estendido aos bancos privados, além dos bancos estatais. Mais uma resposta do governo federal ao comando privatista dos homens de negócio.

\section{À guisa de considerações finais}

Diante do exposto, podemos compreender que a agenda neoliberal não se constrói garantindo a manutenção do bem estar social como compromisso do Estado para as cidadãs e os cidadãos. Em vez disso, os donos do capital exigem que o Estado se

${ }^{29}$ Op. cit., p. 137.

${ }^{30}$ Op. cit., p. 137.

${ }^{31}$ Op. cit., p. 138.

32 Op. cit., p. 138. 
ausente cada vez mais de suas obrigações sociais, a saber, educação, saúde e segurança. A sociedade pretendida pelo ideário neoliberal e capitalista se educa, se cura e se protege na justa medida em que paga por estes serviços, e tanto melhor o serviço mais caro se deve pagar por ele. Não bastasse a intenção de obrigar o Estado a se ausentar, de conspirar para o desmantelamento dos serviços públicos que restam (sobrevivem), o ideário neoliberal e capitalista termina por convencer as pessoas de que é normal que se pague por serviços melhores, criando uma compreensão de naturalização do comércio privado de educação, saúde e segurança. Desse modo, comprar educação, comprar saúde e comprar segurança passa a ser visto como inevitável, a lógica privatista se torna implacável e a resistência a esta "onda consumista" é tomada como disparate. O argumento capitalista, privatista, mercantilista parece invulnerável quando se transpõe o olhar para o âmbito global. A globalização da economia, das necessidades e dos costumes, parece ser a última pedra colocada sobre qualquer intenção de pensar, propor ou agir diferente da situação hegemônica. $\mathrm{O}$ imaginário que as próprias pessoas constroem desmotiva, desmobiliza e sujeita todos aos comandos do capital financeiro. Deve haver resistência, principalmente, contra a construção desse imaginário, e temos a pretensão que a discussão oportunizada no presente artigo contribua com a desconstrução, ao menos com a criação de uma postura crítica, social, humanitária desse e de outros tantos conceitos oriundos do ideário neoliberal.

Enquanto sociedade brasileira, como cidadãs e cidadãos do Brasil, temos visto nos últimos anos, sobretudo nos últimos dois anos, a proliferação de discursos e legislações nominadas normalmente de conservadorismo político, que em alguma medida estão vinculadas ao ideário neoliberal. Temos visto, diuturnamente, direitos trabalhistas serem vilipendiados (vide Lei 13.467/2017, lei da reforma trabalhista), que institucionalizou a flexibilização das relações de trabalho, colocando as trabalhadoras e os trabalhadores à mercê dos acordos feitos com os donos do negócio; a austeridade fiscal tem justificado o congelamento de salários do funcionalismo público, os programas de demissão voluntária, os cortes em todos os setores do cuidado assistencial e da promoção da vida e da formação das cidadãs e dos cidadãos, e a terrível agenda de privatizações, que além de comprometer a soberania nacional, também cede o lugar precioso ao capital privado destinado ao comércio de toda sorte de serviços para a população. $\mathrm{O}$ atual regime de previdência social também está na mira do governo neoliberal e polêmico do Sr. Michel Temer, sendo atacado e corrompido sob a alegação fictícia de estar deficitário e à beira do colapso, sobre esta alegação se constrói um profetismo apocalíptico que ameaça as gerações futuras de não mais conseguirem a aposentadoria. Em contrapartida, desfila diante da população inconformada uma lista de privilégios para segmentos estratégicos dos três poderes da União, segmentos com peso nas decisões e na produção de legislações, para os quais não cessam as concessões de emendas parlamentares e pagamentos de auxílios, concessões que não se coadunam com a situação de austeridade a qual a população vem sendo submetida.

Mas esta história não é recente, desde a década de 1990, o Governo Federal vem cumprindo os compromissos impostos pela agenda neoliberal propalada pela Organização Mundial do Comércio e pelo Banco Mundial. E no caso específico da educação, vimos que ela se tornou objeto de comercialização e submetida à regulamentação destas instituições. Como vimos, todos os parâmetros utilizados para compor as afirmações do relatório do Banco Mundial toma as estatísticas e orientações construídas entre países membros da OCDE, seja países desenvolvidos seja sub ou em desenvolvimento. A educação, portanto, deve ser um produto comercializável submetidos às leis do mercado internacional. Cabe ao Estado, agora, viabilizar esta comercialização, favorecendo a iniciativa privada, estimulando as ações da sociedade 
civil em prol da escola, todavia a intenção não é de trazer a comunidade escolar para a construção de uma educação melhor, antes a intenção é de complementar ou mesmo substituir as responsabilidades do Estado. Cabe a sociedade civil, primeiramente, reconhecer os processos de manipulação que a envolve, em seguida questionar informações e proposições de qualquer espécie que pretenda retirar direitos adquiridos à custa de muita luta de brasileiras e brasileiros que nos antecederam e, por fim, organizar movimentos, mobilizações, enfrentamentos a qualquer discurso, legislação ou ação efetiva do Estado que agrida a dignidade da pessoa, a sustentabilidade do meio ambiente, os direitos humanos ou a soberania do Brasil.

\section{Referências}

ANDIFES. Universidades Federais: patrimônio da sociedade brasileira. Disponível em: http://www.andifes.org.br/wp-content/uploads/2017/11/Andifes-VERSAO-

DOWNLOAD-REDES-SOCIAIS-E-WHATSAPP.pdf

BRASIL. Constituição da República Federativa do Brasil. Disponível em http://www.stf.jus.br/arquivo/cms/legislacaoConstituicao/anexo/CF.pdf. Acesso em 1 fev. 2018.

GRUPO BANCO MUNDIAL. Atingindo uma educação de nível mundial no Brasil: Próximos Passos. 2010. Disponível em:

http://portal.mec.gov.br/index.php?option=com_docman\&view=download\&alias=7289banco-mundial-pdf\&Itemid=30192. Acesso em: 1 dez. 2017. . Um ajuste justo: análise da eficiência e equidade do gasto público no

Brasil. Novembro de 2017. Disponível em: Disponível em: http://documents.worldbank.org/curated/pt/884871511196609355/pdf/121480REVISED-PORTUGUESE-Brazil-Public-Expenditure-Review-Overview-PortugueseFinal-revised.pdf Acesso em: $1 \mathrm{dez} 2017$, p. 1. 